\title{
Theory of Sports: Two Granes Developments
}

\author{
Vasyl Sutula* \\ Kharkiv State Academy of Physical Culture, Ukraine \\ Submission: June 06, 2019; Published: June 27, 2019 \\ *Corresponding author: Vasyl Sutula, Kharkiv State Academy of Physical Culture, Ukraine
}

Abstract

The Purpose of the Study: Is to uncover modern ideas about the two facets of the theory of sports.

Methods of Research: consist in the analysis of special literature, which reveals various aspects of the construction of the theory of sports and the theory of physical culture.

Results of the Analysis: It has been shown that modern sport is a global socio-cultural phenomenon which in its scale has a transnational character. A consensus definition of "sport" is formulated. It is stated that the results of people's activity associated with the use of physical exercises in the process of preparation for and participation in competitions have a dual nature as a person is at the same time the subject and object of the cultural-historical process. A marked feature of the results of the specified activity of people and determines the essence of existence in the theory of sport of two interrelated faces - sociocultural and procedural. It is shown that objective knowledge of the laws of development of sport is possible only within the framework of the theory of physical culture, the main purpose of which is to establish the laws of development of the basic forms of its social manifestation, including sports.

Keywords: Theory; Physical Culture; Sport; Sphere of Activity; Social Phenomenon; Concept

\section{Introduction}

The development of modern society is accompanied by the globalization of all spheres of public life, including the sphere of activity of people connected with the use of physical exercises. This tendency was especially evident in the evolution of the competition-game direction in the development of this sphere, which began to intensively develop at the turn of the 19th century and on the basis of which the social institute of contemporary sports was formed [1]. For more than 200 years of its development, it has become a global socio-cultural phenomenon which, in its scale, has a transnational character, bringing all countries and virtually all social groups into its sphere of influence. According to Ukrainian experts E Imas \& Yu Michudy [2] at the present stage of development of society, sport is not only a socio-cultural phenomenon, it has become a holistic socio-economic system. In its scale, the data given in Article E Mejía [3] indicate that, for example, in the United States in 2006, the financial circle in the field of sports amounted to about 213 billion dollars, and the profit received in this area was 2 and 7 times higher than, respectively, in automotive and cinema industries.

The high social significance of sport stimulated the formation of sports science, the logical consequence of which is the development of a corresponding theory. However, it must be noted that the main directions of research conducted in the field of sports are mainly practical-applied orientation [2]. That is why the opinion is expressed fairly by W Petryński [4]" only theories make science, not facts themselves. Data without a theory is similar to a child without parents". Obviously, the results of experimental research are the basis for checking the existing and the formulation new theoretical positions and hypotheses, that is why their objective interpretation and it is possible within the limits of the corresponding scientific theory. We note that scientific theory, in the modern sense of the concept, is a system of generalized knowledge describing the studied natural or social phenomena and allows to build causal relationships between them and predict their development. This system should be coherent and internally consistent, it should not only describe objects in the corresponding subject area, but also explain their functions, structure, composition, genesis. The construction of knowledge in scientific theory is carried out with the use of an evidentiary mechanism. The immediate cause that makes existing or developing new concepts or theories is the existence of contradictions that cannot be solved within the existing knowledge system. Obviously, the formulated provisions also apply to the theory of sport. In this theory, at this stage of its development, the primary task is to correctly determine the concept of "sport" (?!). As one of its basic constructs. 
The conducted special studies of this problem have shown that there are currently about 200 basic definitions of this concept [5]. The results of these studies also allowed formulating a consensus definition of "sport" that can be reflected in the following form. Sport, as a special socio-cultural phenomenon, is a historically determined activity of people connected with the use of physical exercises, which is aimed at preparing and participating in competitions (activity component of the definition), as well as individually and socially significant results of such activity (the resulting component of the definition) $[5,6]$. From the consensus definition of the concept of "sport" it follows that in the resulting component it focuses on socially meaningful and individually meaningful results of people's activity associated with the use of physical exercises in the process of preparation for and participation in competitions. This feature is a reflection of the fact that a person is at the same time the subject and object of the cultural-historical process. The duality of the nature of the results of the defined activity of people is noted and determines the essence of the existence of two interconnected facets in the theory of sport. They can be conventionally called "sociocultural" and "processal".

Sociocultural branch of the theory of sports. From the above it follows that the activity of people connected with the use of physical exercises and its results should be analyzed, on the one hand, in the context of the development of the cultural-historical process. In this approach, the term "sport" is used for the name of a special social institution that has been formed and evolved as a result of people involved with the use of physical exercises in the process of preparation and participation in competitions.

The strategic direction in this approach is the definition of the social mechanism of self-development of sport, its links with other forms of social manifestation of the sphere of human activity associated with the use of physical exercises, its structure and social functions, its genesis [7]. The results of the research of many scholars show the necessity and importance of this approach in the development of the theory of sport. For example, in the work of G Eichberg [8] focuses on the contradictions that have arisen in the development of the Olympic The movement, as a special sociocultural phenomenon of the present, in the work of K Aisenberg [9] reveals the changes that have taken place in recent years in the social perception of the social status of athletes, in the work of A Guttmann [10] and collective work, edited by R Giulianotti [11] focuses on the importance of studying socio-cultural aspects of the development of this phenomenon, whose results allow us to understand the social essence and the basic laws of the emergence and evolution of sport as a social institution. The main directions of the solution of the above problems are shown in a number of special publications. Thus, the genesis of sport, as a special socio-cultural phenomenon, is disclosed in publications [12,13], its links with other forms of social manifestation of the sphere of activity of people associated with the use of physical exercises are presented in the article [5], and the mechanism of self-development of sport is described in the article [13].

Processal component of the theory of sports. The results of the activities of people connected with the use of physical exercises in the process of preparation and participation in competitions and, accordingly, the phenomenon for whose name the term "sport" is to be considered, on the other hand, to a certain extent as the process of achieving individually meaningful results in a definite individual by a particular individual types of competitive activities of people. It is obvious that the strategic line of development of this trend in the theory of sports becomes the coverage of the procedural component of the specified activity of people, namely, the structure of the multi-year training process, the main approaches to the construction of macro cycles of different levels, the conditions and regularities of building an annual training cycle, its contents, tools, methods and the pedagogical technologies used in it, the principles of its organization, its results and much more. At the same time, the emphasis is first of all on "individually" meaningful results of such activity, namely on raising the level of skill of athletes. This is reflected in the names of the printed publications, which develops precisely this approach to the construction of the theory of sports, for example, "Teaching about training" [14], "Fundamentals of sports training" [15], "The system of training sportsmen in the Olympic sport" [16], «The Training Theory» [17]. In the theory of sports this line is the most developed.

Existing relationship between the sociocultural and procedural components of the theory of sport illustrates the results of the dissertation study ND Bourne [7], which shows the link between socio-economic changes occurring in society and changes in the system of training leading leading athletes. It is also clearly manifested by the example of the answer to the question posed in the article by J Kosiewicz [18] concerning the legalization of doping in sports. Thus, from the consensus definition of the concept of "sport" it follows that the key element in the sport is a specially organized competitive activity. Such activities are regulated by the relevant rules that were formulated and improved in the development of one or another type of sport. The complexity of this process is evidenced by the results of a specially conducted study [13]. Consequently, the existing regulation of the rules of the competition provides a level playing field for all participants. Obviously, use doping in the process of training athletes violates this basic rule of competition, and accordingly, cannot be legalized.

Completing the description of the two facets of the theory of sports, let's pay attention to the following. Sport, as shown above, is one of the directions of the historical evolution of the sphere of activity of people associated with the use of physical exercises. For the name of this sphere, the term "physical culture" is used most often in scientific and social practices [1921]. This means that the theory that describes this sphere of 
human activity is just the theory of physical culture [22-24]. An analysis of the existing definitions of the term "physical culture" made it possible to formulate a consensus definition in such a form. Physical culture is a historically determined activity of people connected with the use of physical exercises (activity component of the definition) and its individual and socially significant results (the resulting component of the definition) $[19,24,25]$. The formulated provisions indicate that holistic representations of sports are possible only within the limits of the theory of physical culture, the main purpose of which is to establish the laws of development of the basic forms of its social manifestation, including sports.

To correctly determine the role of the theory of physical culture in the process of objective knowledge and reflection of the sphere of activity of people associated with the use of physical exercises and its connection with the theory of sports, note the following. First, the object area of the theory of physical culture is the sphere of human activity associated with the use of physical exercises. The subject field in this theory is the social phenomena and processes that arise and develop as a result of the historical evolution of this sphere. Secondly, the object area of the theory of sports is the system of long-term training of athletes, and the field of study - the process of training athletes at various stages of multi-year improvement. The above statement allows us to assert that the theory of physical culture and the theory of sport have different subject fields of cognition. However, the object area of the theory of sports is an integral part of the object area of the theory of physical culture. Consequently, the scientific theories are noted, revealing various facets of the functioning of physical culture in society (the theory of physical culture - the development of physical culture in the context of the cultural-historical process, and the existing theory of sport - to a greater extent, the procedural side of this process) do not contradict, but complement each other by deepening thereby knowledge of the field of human activity associated with the use of physical exercises. They change and develop in accordance with the dynamics of the cognitive process, thus providing an objective understanding of the essence of the social phenomenon of physical culture.

\section{Conclusion}

i. In the course of the above study, a consensus definition of the concept of "sport" was formulated and it was shown that the objective field of sports theory is a system of multiyear training of athletes, and the subject field is the process of preparation of athletes at various stages of multi-year improvement.

ii. It has been established that the results of people's activity associated with the use of physical exercises in the process of preparation for and participation in competitions have a dual nature as a person is at the same time the subject and object of the cultural-historical process. The noted feature defines the essence of the existence of two interrelated facets in the theory of sport - sociocultural and procedural.

iii. In the course of the study, a consensus definition of the concept of "physical culture" was formulated and it was shown that the object area of the theory of physical culture is the field of activity of people associated with the use of physical exercises. The subject field in this theory is the social phenomena and processes that arise and develop in the course of the historical evolution of this sphere.

iv. It has been shown that the theory of physical culture and sports theory do not contradict, but complement each other, thus deepening the system of knowledge about the sphere of human activity connected with the use of physical exercises.

\section{References}

1. Sutula V (2019) Terminologically-conceptual problems of the knowledge of recreational and recreational directions of the development of physical culture of our time, Slobozhans'kyi ScientificSport News 2(70): 5-12.

2. Yasha Y, Mihuda Y (2015) Trends in the development of the sphere of physical culture and sports in the modern market, Yevgeny Imas, Yuriy Mihuda. The theory and methods of physical education and sports 2: 142-149.

3. Eloy Altuve Mejía (2018) Sport, Globalization, Economy, Health, Public Policy and Power. J Phy Fit Treatment \& Sports 3(5): 555623.

4. W Petryński (2018) Theory and Experiment in the Science on Human Behavior. J Phy Fit Treatment \& Sports 5 (5): 555672.

5. Vasyl Sutula (2018) Summarizing the definition of the concept of "sport" as one of the basic constructs of the generalizing theory of physical culture and sports theory. Slobozhansky Scientific and Sport News 1(64): 89-97.

6. Vasil S (2018) General Definition of the Concept Sports. J Phy Fit Treatment \& Sports 4(4): 555644.

7. Bourne ND (2008) A history of teaching theory and methods for elite runners through 1975. Dissertation a Doctor of Philosophy at the University of Texas at Austin p. 499.

8. Henning Eichberg (2009) Culture of Olympic and other movements: exception, recognition, holiday. Logos 6 (73): 58-81.

9. Eisenberg K (2006) Athlete. Christina Eisenberg Logos 3(54): 3-22.

10. Alen Guttmann (2016) Ot rituala k record: priroda sovremennogo sport [From Ritual to Record: The Nature of Modern Sports]. Gaidar Institute Press, Moscow.

11. Giulianotti, Richard (2004) Sport and Modern Social Theorists. London pp. 252.

12. Vasyl Sutula (2017) Cultural and Historical Origins of Modern Sport (the first message). Slobozhansky Scientific and Sport Newspaper 6(62): 107-112.

13. Vasyl Sutula (2018) Cultural and Historical Origins of Modern Sport (Second Message). Slobozhansky Scientific and Sport Bulletin 2(64): 73-81.

14. Vasyl Sutula (2017) Conceptual provisions of the generalization theory of physical culture. The theory and methods of physical education and sport 3: 107-115. 
15. Harre D (1971) Teaching about training. Moscow: Physical Culture and Sport pp. 254.

16. Matveev LP (1977) Basics of sports training. Tutorial for In-Physical Training. Moscow: Physical Culture and Sport pp. 271.

17. Platonov VN (2015) System of training in Olympic sports. General theory and its practical applications: a textbook (for trainers): 2 books. K: Olympus Lit Kn $1^{\text {st }}$ pp. 680.

18. Dragan Milanović (2013) Training Theory. University of Zagreb Faculty of Kinesiology. Zagreb, pp. 523.

19. Jerzy Kosiewicz (2018) Considerations about Doping in Sport: A New Solution. J Phy Fit Treatment \& Sports 2(3): 555590.

20. Sutula VO (2016) Physical culture: the prerequisites of the theory. The theory and methods of physical education and sport 3: 60-65.
21. Brown DHK (2019) Physical Culture [Editorial]. Societies 9(1): 23

22. Vasil Opanasovich Sutula (2018) Generalizing the Definition of “Physical Culture". J Phy Fit Treatment \& Sports 2 (3): 555586.

23. Sutula VA, GV Vlasov (2013) The theory of physical culture: a scientific myth or reality? The theory and practice of physical culture 35: 10-14.

24. Vasyl Sutula (2017) Conceptual provisions of the generalization theory of physical culture. The theory and methods of physical education and sport 3: 107-115

25. Vasil Opanasovich Sutula (2018) Problems and Perspectives of Construction of the Generalized Theory of Physical Culture. J Phy Fit Treatment \& Sports 3(4): JPFMTS.MS.ID.555620.

\section{Your next submission with Juniper Publishers} will reach you the below assets

- Quality Editorial service

- Swift Peer Review

- Reprints availability

- E-prints Service

- Manuscript Podcast for convenient understanding

- Global attainment for your research

- Manuscript accessibility in different formats

(Pdf, E-pub, Full Text, Audio)

- Unceasing customer service

Track the below URL for one-step submission https://juniperpublishers.com/online-submission.php 